\title{
Research on Constructing the "People-Oriented" View of Modern Physical Education
}

\author{
Haiting Li \\ Department of Physical Education, Henan University of Animal Husbandry and Economy \\ Zhengzhou, Henan 450046
}

\begin{abstract}
With the improvement of the national economy, people's quality of life is getting better and better. While pursuing material enjoyment, people have begun to pay attention to the construction of spiritual civilization. Physical education is an important part of spiritual civilization construction. Physical education can not only make people healthy, but also enrich people's spiritual world. Then, in the actual education and teaching, how to do this work well? This paper will analyze the construction of modern physical education concept from the perspective of "people-oriented", in order to better develop the cause of physical education in China.
\end{abstract}

Keywords-People-Oriented; Modern Sports; Educational Concept; Construction

\section{INTRODUCTION}

With the continuous deepening of quality education, the development of physical education and the promotion of students' all-round development have gradually received more and more attention. As an important part of China's education, physical education is of great significance in improving students' physical quality and maintaining students' physical health. Building a "people-oriented" modern physical education concept can highlight the students' main status and promote physical education. The improvement of teaching quality will further promote the sustainable development of sports education. The "people-oriented" proposal reflects the great transformation of human society in the concept of development, and marks the re-recognition and reflection of human beings in the development of today's society. "Peopleoriented" will become the main theme of sports development in the new century. The construction of the "people-oriented" modern sports education concept will surely become an important direction of modern physical education reform.

\section{The CONNOTATION OF "PeOPle-ORIENTED" MODERN SPORTS EDUCATION CONCEPT}

People-oriented is actually a new development concept put forward by the traditional "material-oriented" thinking. The "people" is placed in the most important position and is regarded as the foundation and guarantee for building a harmonious society. In China's economic construction, the emphasis has always been on the rapid development of the economy. To a certain extent, it has neglected or even damaged the needs and interests of the people. The scientific concept of development has increased the emphasis on "people" and carried out the "people-oriented" development thinking has a very positive effect on the development of various fields and industries in China. Physical education is an important part of China's education, and it is also the key to improving the physical quality of the people and maintaining their health. It is also necessary to attach importance to the "people-oriented" thinking and implant them into the concept of modern physical education, making physical education more human. Students can get a certain growth and improvement in the teaching process. Under the guidance of the "people-oriented" thinking, the significance of physical education can be highlighted, and the educational values of educators can be reformed, making it a clearer and more accurate understanding of the goals of physical education.

\section{THE IMPORTANCE OF CONSTRUCTING THE "PEOPLE- ORIENTED" MODERN SPORTS EDUCATION CONCEPT}

The emphasis on "people" is an important guarantee for the harmonious development of society. In the current process of the great rejuvenation of the Chinese nation, paying attention to "people" and practicing the "people-oriented" development thinking is very helpful to the development of our country's various fields. Sports, as an important branch of China's development process, should also put the "peopleoriented" thinking to the status of guiding ideology, and put the "people-oriented" thinking into the minds of physical education educators in the process of physical education, and in actual action the important role of the "people-oriented" thinking is played. Here, the significance of constructing the "people-oriented" modern sports education concept is summarized as follows.

Physical education is aimed at "people". Only by respecting people, attaching importance to people, and encouraging people to participate in physical education can we give full play to the role of physical education and enhance the effectiveness of physical education. Under the current situation of the urgent need for the development of China's physical education, it is very helpful to build a "peopleoriented" modern sports education concept to improve the development speed of China's physical education, and to ensure the steady progress of China's sports education. China's long-term educational practice, including physical education practice, has shown that the guiding role and promotion role of the "people-oriented" education concept for education is difficult to estimate. In the current situation of China's 
physical education entering a new era, it should be more profound.

Physical education work requires educators to have sufficient sense of responsibility, dedication and crisis. In the sports educators, promoting the "people-oriented" modern sports education concept has a great responsibility to improve the physical education workers. People-oriented thinking emphasizes that educators pay attention to the personal situation of educated people in their work, attach importance to the teaching effect of each educated person, and put the "people-oriented" modern physical education concept into the minds of physical education educators. It can enhance the responsibility of sports educators, and create a sense of mission and purpose, so that they are responsible for their actions; on the other hand, they can also improve the working ability of physical education educators to some extent, because under the condition of having the responsibility of education, if physical education educators want to improve the quality of their work, they will work hard to learn relevant knowledge and skills and improve their working ability.

The purpose of physical education work is not only to train the physical fitness of the educated, to improve the sportsrelated skills of the educated, but also to require the physical education work to improve the moral quality and cultural knowledge of the educated. Carrying out physical education under the "people-oriented" modern physical education concept is of great benefit to improving the comprehensive ability of educated people and ensuring their comprehensive development. The "people" in the people-oriented system includes all aspects of human ability, emphasizing the allround development of people. Putting the "people-oriented" concept of education into modern physical education can enable physical education educators to pay attention to the education of their cultural knowledge, ideology and morality while ensuring their access to relevant sports while educating educators. At the same time of skills, we can also ensure the full development of our moral, intellectual, physical and aesthetic. It can be said that improving the comprehensive ability of educated people is an important reason for putting the "people-oriented" modern physical education concept into physical education, and plays an important role in China's strategy of strengthening the country through talents.

\section{The Strategy of Building the "PeOple-Oriented" MODERN SPORTS EDUCATION CONCEPT}

In the development of sports education, educators have always paid more attention to improving the physical ability of educated people. Some educators even mistakenly believe that when educating, they only need to improve their education. The physical ability of sports, so that they have mastered certain sports skills is enough. As for other aspects, such as ideological and moral education, the establishment of values and worldview, and sports education has no concern. This traditional concept of education is extremely unfavorable to the development of sports education in China, ignoring the real needs of educated people. In education and teaching, although it is not wrong to improve the physical fitness of the educated, they have the relevant sports skills. However, from the perspective of the long-term development of sports, it has many drawbacks, such as the unhealthy development of the physical and mental health of the educated, making the physical education work too utilitarian.

In physical education, the most significant and most crucial goal is to improve students' physical ability and deepen their physical potential. However, in the modern concept of physical education, the goal of physical education is actually not unique. The traditional concept of physical education puts the focus of teaching on the "object", pays attention to the achievements of physical education and pays attention to the development of sports, but does not pay attention to students, and does not pay attention to the construction of physical education. This is sports. In contrast, the modern sports education view believes that in physical education, we must pay attention to the connotation of "people" in order to truly realize the modernization and human culture of physical education, and also promote the rapid development of modern physical education in China. Based on the background of the reform of physical education in China, physical education teachers should understand the importance of "people" in physical education, update their own concepts in time, and turn the emphasis on "things" in traditional physical education into "people". Paying attention to and adhering to humanism, on the basis of cultivating students' sports skills, paying attention to the overall development of students, emphasizing the education of all aspects of morality, intelligence, beauty and beauty, enabling students to achieve continuous improvement on the basis of the concept of "people". Not only that, the change from "material" to "human" is an important manifestation of the "people-oriented" thinking, and is the primary content of the modern sports education reform. It is improving the comprehensive strength of physical education and achieving the goal of physical education. The aspect is significant.

Therefore, in the development of sports education, to build a "people-oriented" concept of modern physical education, we must first change the concept of educators, so that they recognize the importance of "people" in the development of sports education, the traditional physical education the emphasis on "things" has shifted to the emphasis on "people". It is necessary to realize that in the development of physical education, it is not just to pass on some superb sports skills to the educated, so that it is enough for them to exercise a strong body. In the construction of the "people-oriented" modern sports education concept, sports workers should also recognize that the importance of the long-term development of physical education should promote the all-round development of educated people and make them aware of the importance of sports.

In the excessive physical education, the goal of physical education in China has always been clear, that is, to improve the individual sports ability of the educated, to achieve a good ranking in various competitions or examinations, to constantly surpass themselves and achieve physical education. Although there is no obvious error in this kind of education and teaching concept, when constructing the "people-oriented" modern sports education concept, it has obvious irrationality, because this educational concept is largely ignored. For example, educators who receive physical education and actively 
complete various trainings may not want to achieve excellent results in competitions or exams, but only because they like sports, sports, such as playing football. When playing basketball, they can make their body and mind feel happy.

In traditional physical education, the main goal is to improve students' personal sports ability, ensure that they are proficient in sports skills, and achieve excellent results in the competition. In the modern sports education concept, such educational goals actually run counter to the "people-oriented" educational goals. In the "people-oriented" modern sports education concept, the emphasis is on "people" rather than "things". Focusing on the development of "people", we will not blindly focus on sports performance. Under the background of quality education, education and teaching work focuses on improving the overall quality of students, and advocates the cultivation of all-round talents. The same is true for modern physical education. Under this circumstance, the goal of physical education has gradually changed. It is no longer only concerned with the students' sports performance, but also the cultural knowledge and the cultivation of moral quality. Compared with the traditional sports education goals, it is undoubtedly more reasonable and perfect. The humanistic embodiment of the goal of physical education is actually an important part of building a "people-oriented" modern sports education concept. At this stage, China's sports and career are at a new stage of development, and it is necessary to scientifically practice "people-oriented". Provide a good guarantee for the stability, health and sustainable development of sports, and guide China's sports

Therefore, in the development of sports education, the establishment of sports goals should not be too utilitarian, but should fully respect the goals of the educated, not just focus on the individual's sports performance, excessive Paying attention to gains and losses, this is also extremely unfavorable for the development of China's sports education. Imagine if an athlete is very good at various competitions, but he does not have correct values and outlook on life and his morality is ruined. Such athletes may never grow into excellent athletes, nor can they reflect China's sports. Therefore, in the construction of the "people-oriented" concept of modern physical education, educators should improve their educational philosophy and realm, not just focus on one or two sports events, but should be based on educated The need for long-term development of physical education, training allround talents, and setting educational goals for scientific nursing, so that each educated person can feel the meaning of learning sports knowledge when receiving physical education, and truly enhance the significance of physical education and value.

The combination of "humanistic spirit" and "scientific spirit" may be seen by many educators. Physical education has little to do with the spirits of "humanities" and "science". When educators receive physical education, the main focus is still on physical training. However, this narrow view of physical education is obviously not applicable to the "peopleoriented" concept of modern physical education. In modern physical education, "science and humanities" is the foundation of the development of this educational concept.
Science and humanities are the two key words of modern physical education. The combination of humanistic spirit and scientific spirit is also an important manifestation of the difference between modern physical education concept and traditional physical education. The humanistic spirit reflects a kind of value, which is the manifestation of human's own emotions and emotions of others. The scientific spirit is a manifestation of thinking ability, which shows the objective laws followed by the development of human society and sports. The integration of humanistic spirit and scientific spirit is an important part of modern physical education in China and an improvement direction of traditional physical education in China. In the face of China's rapid development of sports, we must implement the combination of humanistic spirit and scientific spirit, not only to let physical education educators correctly understand the connotation of humanistic spirit and scientific spirit, but also to make relevant physical education workers practical. Practice the humanistic spirit and scientific spirit in the work, ensure the scientific nature of the development of China's physical education, and ensure that the development of China's sports education reflects the important idea of "people-oriented". Although physical education and other kinds of education are fundamentally different, the essence of education is the same, that is, to cultivate all-round development talents with outstanding sports ability. Therefore, the combination of humanistic spirit and scientific spirit in general education is the same applies to physical education.

Humanistic spirit and scientific spirit can be said to be the foundation of the development of modern physical education in China. During the work of physical education educators, if they can't understand the connotation of humanistic spirit and scientific spirit, it is only a matter of talking about the development of "people-oriented" modern physical education. For educators, they only have a deep understanding of these two. Only in this way can we know what kind of physical education we need, and only in this way can we truly demonstrate the important idea of "people-oriented" in China's sports education.

The essence of quality education based on national innovation is the subjective education, which is to cultivate students' subject consciousness, develop students' subject ability, and shape students' main personality as the purpose of various education and various teaching activities. . As far as its macroscopic level is concerned, quality education is a kind of national education; as far as its micro level is concerned, it is a kind of education with individualized education and harmonious development of individual quality. On the one hand, we must pay attention to the socialization of the educated, strive to optimize and develop the overall educational environment, and cultivate the subject personality and active activity ability suitable for modern society; on the other hand, we must pay attention to the cultivation of individual quality and develop the individuality of the educational object.

Under the guidance of modern educational concepts, students are the main body, and through active learning, the teaching ideas and teaching methods that promote the development of subjectivity are aimed at respecting the 
subjective position and subjective personality of students, cultivating students' autonomy, initiative and creativity, and constantly mastering Humans have excellent scientific and cultural knowledge, learn to survive, learn to be a human being, learn to learn, learn to create, participate in the main body, learn cooperatively, pay attention to the development of differences and experience success, experience the dignity and greatness of human nature and the meaning and value of human beings. The inner life force of oneself breaks through the predicament and transcends the sorrow. Through the profound experience of the affliction situation, it fosters human dignity and life value, and enhances the subject personality and spiritual realm.

From the beginning of modern education, many educators regard the cultivation of personality as the most important content of education. Without respect and development of personality, there is no modern education. In the new century, the reason why we propose modern personality education is this. Developing people's ability to innovate is an important aspect of physical education. Physical education is to develop people's "subjectivity" through their own physical and mental activities, cultivate strong will and sound personality and good social adaptability, and correctly understand and participate in interpersonal relationships. Good way. Physical education "is the result of people's health, strength and beauty as their cultural goals". Sport is the self-cultivation of one's own body and mind. Obviously, this is a physical and mental activity that consciously optimizes oneself. Health is a very important aspect of the physical and mental existence of human life, which requires physical education to emphasize the establishment of "subjective" personality. In the historical process of entering the 21 st century, educational thought is undergoing a tremendous transformation. There is a strong melody that is under the humanistic education thought, "'Educating people's non-manufacturing devices"" to change the past to regard people as "labor tools" and "moving tools" while ignoring human subjectivity thought of. "From a philosophical point of view, subjectivity is the most important feature of personality function. The presence or absence or strength of a person's subjectivity is marked by the level of creativity or creativity. Subjectivity is a kind of personality.

\section{CONCLUSION}

In summary, the construction of the "people-oriented" concept of modern physical education should be based on the promotion of human life meaning and value meaning. The "people-oriented" modern physical education concept focuses on shaping the ideal personality of the educated, fully complying with Respecting the law of human physical and mental development, safeguarding people's rights, caring for people's difficulties and pains, tolerating people's weaknesses and shortcomings, developing people's autonomy and independence, etc., to encourage and promote the generation and maturity of human creative talents. Constructing the "people-oriented" modern sports education concept is the inevitable requirement of social development under the new era. Only when the quality of the entire nation is improved can the main body of modern civilization be formed, and the corresponding advantages of intelligence and human resources can be produced, so that the implementation of the sustainable development strategy can have a basic guarantee and real motivation.

\section{REFERENCES}

[1] Chen Hao. Analysis of People-oriented Modern Physical Education Teaching Research [J]. Family Education World, 2013 (18): 117.

[2] Feng Chao, Wang Leitao. Research on the Construction of Modern Sports Education View Based on People-oriented [J]. Youth, 2014(3).

[3] Song Zhenghua. Research on the Construction of Modern Sports Education Concept Based on "People-Oriented"[J]. Sports world ,2013(9):86-87.

[4] Hurricane Lei. Constructing the modern sports education concept of "people-oriented" in college sports [J]. Examination Weekly, 2014(89): 103-104.

[5] [5] Feng He. Research on the Construction of "People-Oriented" Modern Sports Education View [J]. Grand View, 2016(1): 77-78. 